\title{
The 'difficult' colonic polyp
}

CHRISTOPHER B WILLIAMS, BM, FRCP

\begin{abstract}
With improved instrumentation and endoscopic technique coupled with the pre-injection of an adrenaline/sclerosant mixture, nearly all pedunculated polyps can be rapidly and relatively easily removed. Only a few very large broad-based or sessile polyps require referral to the surgeon; even some of these can be managed endoscopically if the patient is unfit or unwilling for surgery, but willing to undergo multiple repeat endoscopies. Can J Gastroenterol $1990 ; 4(9): 533-536$
\end{abstract}

Key Words: Colonic polyps, Polypectomy

\section{Le "difficile" polype du côlon}

RESUME: Grâce à l'amélioration des instruments et des techniques endoscopiques associée à la pré-injection d'un mélange adrénaline/agent sclérosant, l'exérèse de presque tous les polypes pédonculés est relativement rapide et aisée. Seuls les quelques polypes sessiles de très grosse dimension et à base large requièrent l'intervention du chirurgien; mais même certains de ceux-ci peuvent être traités par endoscopie si le patient ne peut subir une opération chirurgicale ou ne le souhaite pas, et s'il est par contre prêt à accepter l'éventualité d'endoscopies multiples répétées.

$\mathrm{D}$ IFFICULTY IS A RELATIVE TERM. A polyp which may seem difficult, dangerous or even impossible for an inexperienced endoscopist to remove may be easily managed by an expert. Difficulty may occur in seeing the polyp adequately because of positional problems which can be removed or improved either by changing the patient's position or by rotating the instrument appropriately. In the narrow diameter, often fixed lumen of a patient with diverticular disease, movements of the snare for polypectomy may be restricted and difficult, but the polyp usually proves to be smaller than expected (since judgement of size is by comparison with the lumen), so that transsection is actually easy.

Conversely it is possible to underestimate the dimensions of polyps in the cecum. A number of papers testify to the fact that size alone is no barrier to endoscopic polypectomy (1-5). The tendency of most colonic polyps to be on a relatively thin stalk of normal
St Mark's and St Bartholomew's Hospital, London, United Kingdom

Correspondence and reprints: Dr CB Williams, St Mark's Hospital for Diseases of the Rectum and Colon, City Road, London ECIV 2PS, United Kingdom tissue makes most polypectomies easy. The endoscopist should optimize the view before snaring by changing the patient's position to allow gravity to contribute and by rotating the instrument appropriately to place the polyp in the lower part of the view for easier snaring. Prodding the polyp helps to assess its mobility and configuration. Snare placement is achieved primarily by maneuvring the instrument tip, since torque-stable snares rarely work well when the endoscope and colon are angulated. With a little imagination and practice the snare loop can be made to slide or roll over the polyp head one way or another. Usually the part of the loop nearer the endoscopist is pushed onto the exact region of the stalk where closure is intended before closing (push method), but for very long or floppy stalks it can be more convenient to catch the stalk in the furthest part of the loop, and to advance the snare somewhat as the loop closes (pull method).

\section{SNARING}

By holding the $2 \mathrm{~mm}$ snare outertube against it for reference, it is easy to make a judgement as to the size of the stalk. However, a large polyp occupying much of the lumen may make a more than partial view impossible, in which case the critical part to see is the upper stalk, so that the presence of sufficient coagulation can be ensured before transsection of the polyp. 


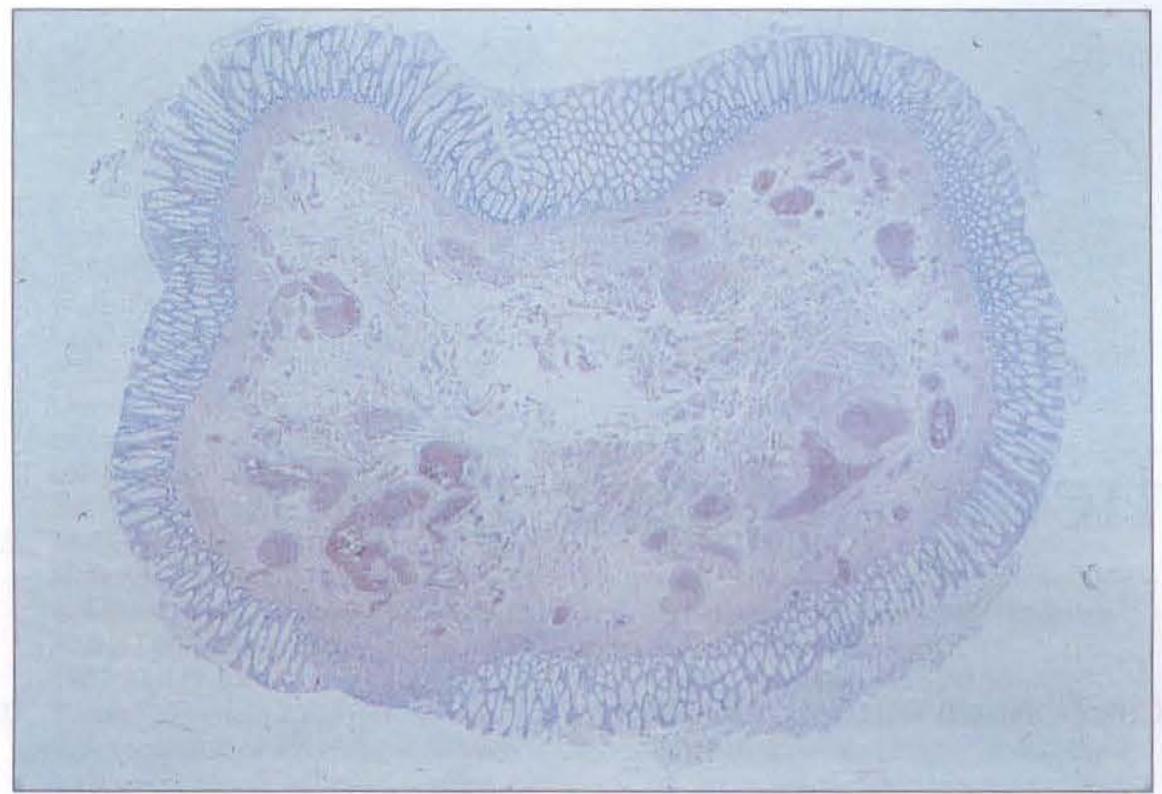

Figure 1) Histological cross section of a polyp stalk which previously bled post polypectomy. Note central electrosurgical necrosis but intact peripheral blood vessels

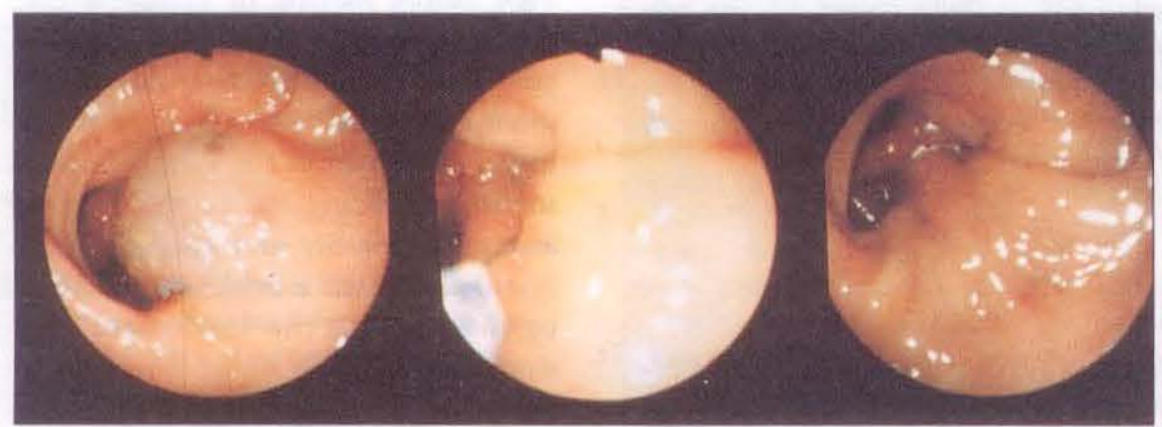

Figure 2) Stages in pre-injection (adrenaline and sclerosant) of large stalk (left); needle insertion (middle); injected stalk (right)

Transsection is rarely a problem, whereas first achieving adequate coagulation of the stalk vessels may be difficult. A plexus of feeding vessels is drawn up into the stalk from the submucosa, the whole of which must be occluded (by edema or hemocoagulation) to prevent bleeding (Figure 1). Since some of the arteries may be relatively thick-walled, the whole stalk must be heated in both centre and periphery, and preferably for a depth of several millimetres to ensure adequate hemostasis. It is sometimes obvious after transsection that the upper stalk is insufficiently swollen/whitened for long term safety, in which case it is easy to re-snare the residual stalk gently lower down, apply extra heat and then release the loop again without re- swelling/whitening indicates sufficient electrocoagulation and the snare can be tightened for transsection. For larger stalks it is logical to increase the power somewhat to speed the process, but too high power settings risk inadequate depth of heating, especially at the core of the polyp.

Blend or cut current is not generally used, although at comparably low power settings versus coagulating current there may actually be little effective difference, and at high power, coagulating current can 'cut' with little depth of heating. Nonetheless during piecemeal removal of sessile polyps, especially in the thin-walled proximal colon, there may be a safety factor in using blend or cut current to transsect quickly, minimizing the depth of tissue damage.

\section{INJECTION OR PRE-INJECTION}

The use of the flexible endoscopic sclerotherapy needle to inject 2 to 10 $\mathrm{mL}$ adrenaline $(1: 10,000)$ submucosally at a post polypectomy site if bleeding occurs can be as effective in the colon as it is in management of upper gastrointestinal bleeding. It may be logical to use saline (even twice normal saline) rather than water as a diluent to prolong the duration of the injected

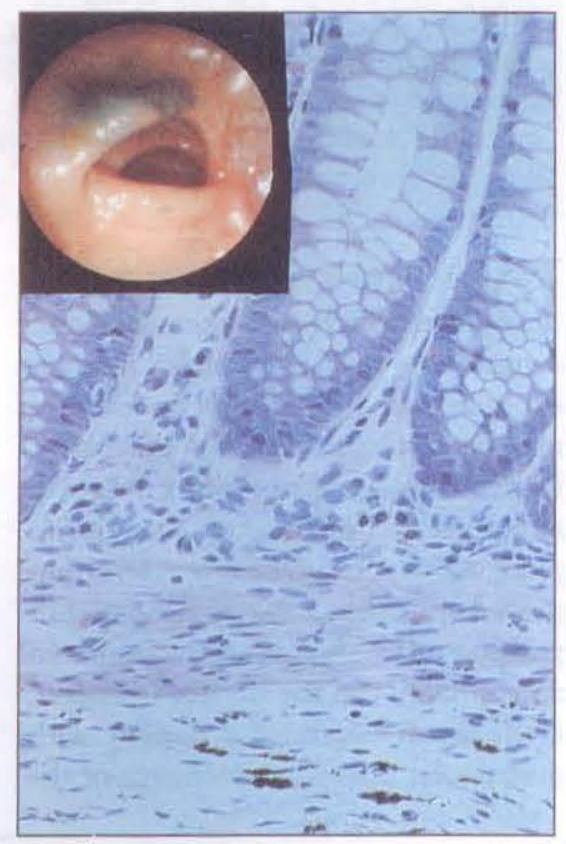

Figure 3) India ink tattooing. Histological section showing submucosal carbon particles and (inset) the blue-grey appearance at endoscopy 


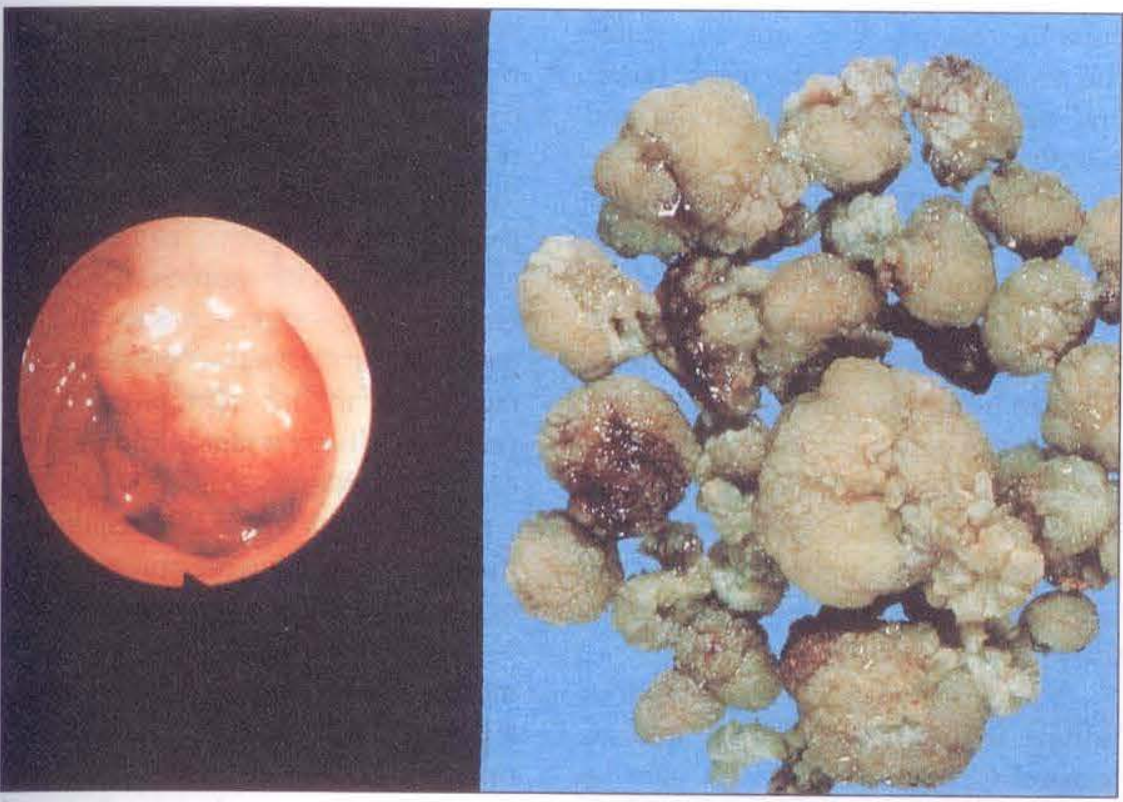

Figure 4) Sessile polyp specimens (left) before and (right) after multiple piecemeal polypectomy

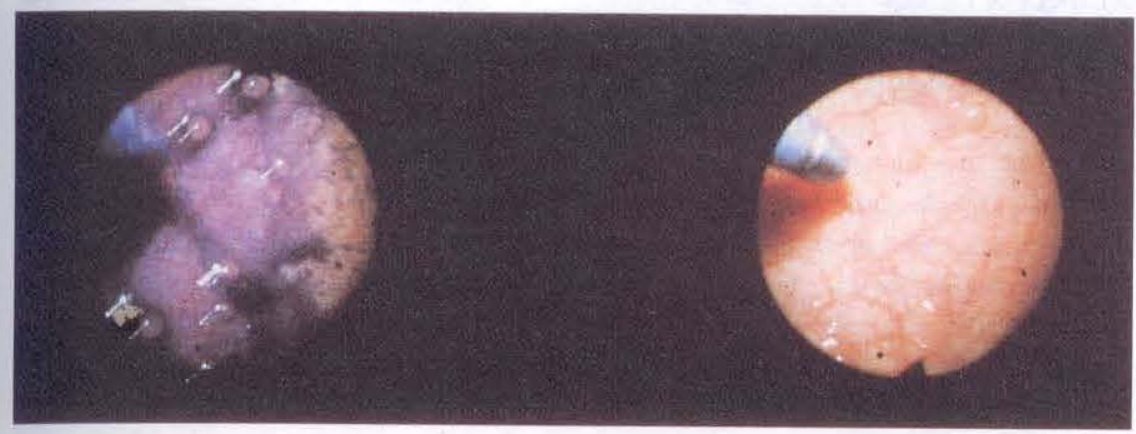

Figure 5) Dye spray with diluted blue pen ink showing 0.5 to $1 \mathrm{~mm}$ adenomatous polyps in an adenomatous polyposis subject (before and after)

bleb compared to the rapid diffusion of aqueous solution.

Pre-injection of adrenaline into the basal part of broad-based polyps appears to be an effective adjunct against bleeding before snaring and electrocoagulation. Pre-injection gives the added advantage that constriction of vessels in the polyp head also prevents the anxiety-provoking back bleeding which may occur after snaring.

Pre-injection is mainly done using 1 $\mathrm{mL}$ of a 50:50 mixture of 1:10,000 adrenaline with sclerosant (such as $1.5 \%$ STD solution) for thick stalks, which otherwise have a significant risk of immediate or delayed hemorrhage (Figure 2). Injection of sclerosant too near the bowel wall is dangerous, but injected into mid stalk, leaving sufficient space to snare above it, the result is a near guarantee of a completely bloodless procedure. It is a matter of opinion as to when to use pre-injection. The author injects any stalk usually above $1 \mathrm{~cm}$ in diameter, especially if the base is conical with converging folds a configuration which can prove difficult to electrocoagulate adequately.

Adding a minute quantity of methylene blue to colour the solution slightly helps to show any leakage or to assess the extent of successful injection. However it is better not to add methylene blue for injection after bleeding, because the admixture of red and blue makes black.

\section{TATTOOING}

Large, possibly malignant, or sessile polyps need careful follow-up. Tattooing by the method of Ponsky (6) or others (7) makes follow-up localization easy. A standard sclerotherapy needle is used to inject a $1 \mathrm{~mL}$ submucosal bleb of dilute sterilized India ink, which is simply a carbon suspension. The black particles can be seen on microscopy to be trapped in the submucosa, or endoscopically as a blue-grey stain under the surface (Figure 3). Patients have had unchanged tattoos for over five years of follow-up; the likelihood is that the stain will persist lifelong.

Tattooing is also useful to the surgeon or histopathologist for localization if surgical resection becomes necessary. If a sufficiently large (perhaps $5 \mathrm{~mL}$ ) volume is used, the stain should be visible serosally. However some attempts at tattooing backfire with considerable black staining of the lumen, so that it is wise to finish polypectomy and retrieve specimens before tattooing.

\section{SESSILE AND \\ BROAD-BASED POLYPS}

Sessile or broad-based colonic polyps may need piecemeal snare removal. Laser photocoagulation of sessile polyps is unsafe above the rectum except in very expert hands $(8,9)$, whereas judicious use of the snare, if necessary on several visits, is both effective and acceptably safe. Piecemeal removal is mainly necessary because too large portions cannot be effectively managed with the snare loop except using an excessively high power current. There is also a significant risk of full thickness damage to the bowel wall, especially if the serosa is tented up within a broad stalk, or bunched up into the snare loop when closing over a sessile polyp more than 15 to $20 \mathrm{~mm}$ in diameter.

In snaring piecemeal the rule is "not to bite off more than you can chew." Twenty to 30 specimens of various sizes may result (Figure 4), but smaller portions are safer to remove and may be aspirated into the filtered polyp suction trap (Endodynamics Ltd) for histological examination. Residual basal tissue can be electrocoagulated with the snare tip or a ball electrode. This results in a large shallow local ulcer which heals in about three weeks.

For 'clam-shell' polyps, wrapped around an angle or haustral fold in the 
proximal colon, it may be necessary to invert the instrument tip and finish piecemeal removal in retroflexion. Some practice may be needed to impact the tip of the snare loop into the mucosa and then use instrument torque and angulation to swing the loop crosswise to snare the polyp transversely along the haustral fold.

At various times during a difficult piecemeal polypectomy the patient should be asked if any pain is being experienced.

Serosal heating causes immediate pain, which is an indication to terminate the procedure (although fortunately overdistension is the more usual, and immediately reversible, cause).

\section{VERY LARGE OR MULTIPLE POLYPS}

A sense of proportion must be maintained by even the most enthusiastic endoscopist. There are patients who merit surgery or at least a modified surgical approach. As a compromise procedure huge (4 to $5 \mathrm{~cm}$ )'polyps in the rectosigmoid colon can sometimes be snared and intussuscepted down to the rectum for local surgical removal under anesthesia (10); if the polyp can be pulled down so that it can be felt by the endoscopist's examining finger per rectum it should subsequently intussuscept into or through the anus when the patient is asleep and the pelvic mus-

\section{REFERENCES}

1. Nivatvongs S, Snover DC, Fang DT, Piecemeal snare excision of large sessile colon and rectal polyps: Is it adequate? Gastrointest Endosc 1984;30:18-20.

2. Dagradi AE. Colonoscopic polypectomy excision of a large villous adenoma. Am J Gastroenterol 1976;66:464-6.

3. Bedogni G, Bertoni G, Ricci E, et al. Colonoscopic excision of large and giant colorectal polyps. Technical implications and results over eight years. Dis Colon Rectum 1986;29:831-5.

4. Christie JP. Colonoscopic excision of culature relaxed. The surgeon, unlike the endoscopist, can use both hands and tie ligatures to ensure rapid and completely safe removal.

An attempt should always be made to snare large polyps, even if the attempt is unsuccessful and surgery becomes indicated. Frequently the previous assessment of size (whether on $\mathrm{x}$-ray or by another endoscopist) is incorrect, the polyp usually proving to be smaller than expected. Even very large polyps may have relatively thin stalks, and those with larger stalks can be managed easily and safely after pre-injection as described above.

A patient having 30 to 40 obvious polyps (other than known hamartomatous polyposis subjects) may be better managed by surgery rather than by heroic polypectomies with the prospect of infrequent follow-up thereafter. Multiple biopsies, including some from the smallest polyps seen (perhaps after dye spray using diluted blue ink, Figure 5) should prove or disprove a diagnosis of adenomatous polyposis. If appropriate, the larger polyps can be removed or destroyed.

\section{RETRIEVAL OF LARGE OR MULTIPLE SPECIMENS}

There is an obvious onus on the endoscopist to obtain possible tissue for histological examination. With single very large polyps it is easy to catch the

sessile polyps. Am J Gastroenterol 1976;66:23-8.

5. Gyorffy EJ, Amontree JS, FenoglioPreiser CM, Gogel HK, Blessing LD. Large colorectal polyps: Colonoscopy, pathology and management. Am J Gastroenterol 1989;84:898-905.

6. Ponsky JL, King JF. Endoscopic marking of colonic lesions. Gastrointest Endosc 1975;22:42-3.

7. Poulard JB, Shatz B, Kodner I. Preoperative tattooing of polypectomy site. Endoscopy 1985;17:84-5.

8. Kiefhaber P. Indications for endoscopic neodymium-YAG laser treatment in the gastrointestinal tract. head or stalk in the snare loop and withdraw the trophy to the rectum. In patients with good sphincter tone it can then prove frustratingly difficult to pull the polyp through the anus, even with the patient attempting to bear down and expel it. The simplest - if mildly embarrassing - approach is to have the patient squat on the floor over a suitable receptacle; in this more physiological position delivery is rapid and easy (with or without snare assistance).

Multiple polyps often require reinsertions of the instrument, but a split overtube can be used to speed matters.

Alternative use of a second instrument has been suggested (11), which is a counsel of despair, since insertion is not usually very easy. Long-nosed retrieval snares, condom-catchers and other devices have not proved very successful, but the 'tidal wave' technique works reasonably well. The colonoscope is passed to the splenic flexure (with all polyps or fragments previously placed distal to this). A $50 \mathrm{~mL}$ syringe is used to instill at least 500 to $600 \mathrm{~mL}$ tap water through the instrumentation channel, followed by air insufflation until the patient feels uncomfortable.

The colonoscope is withdrawn and a phosphate enema immediately instilled into the rectum. In a short time all or most of the specimens will be (explosively) passed.

Twelve years' experience. Scand J Gastroenterol 1987;2:53-63.

9. Brunetaud JM, Maunoury V, Cochelard D, Boniface B, Cortot A, Paris JC. Endoscopic laser treatment for rectosigmoid villous adenoma: Factors affecting the results.

Gastroenterology 1989;97:272-7.

10. Gillespie PE, Nicholls RJ, Thomson JPS, Williams CB. Snare polypectomy by sigmoid-rectal intussusception. Br Med J 1978;1:1395.

11. Banez AV, Bozek SA, Simon RF. A double endoscope method for multiple colonic polypectomy. Gastrointest Endosc 1987;33:30-2. 


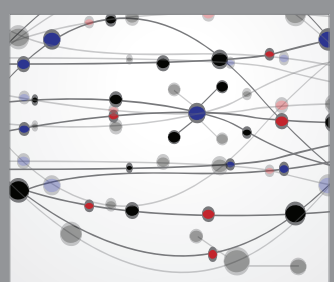

The Scientific World Journal
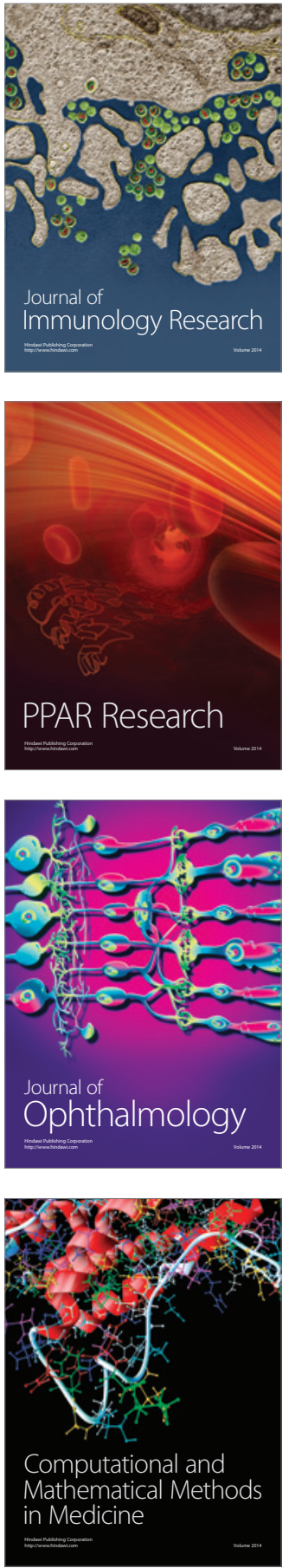

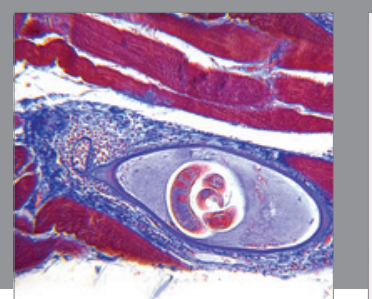

Gastroenterology Research and Practice

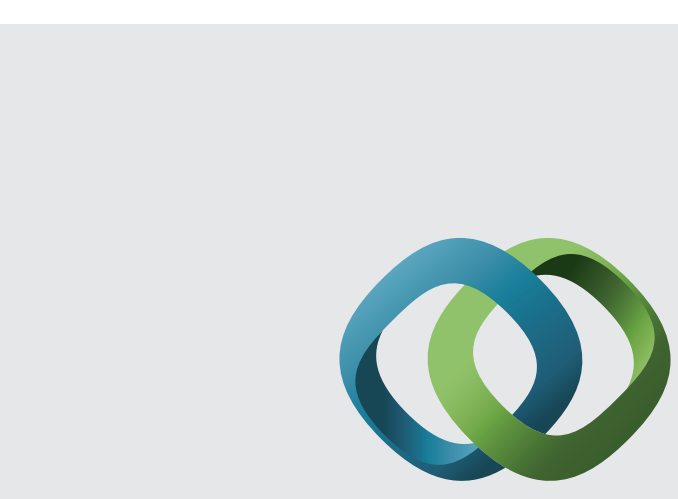

\section{Hindawi}

Submit your manuscripts at

http://www.hindawi.com
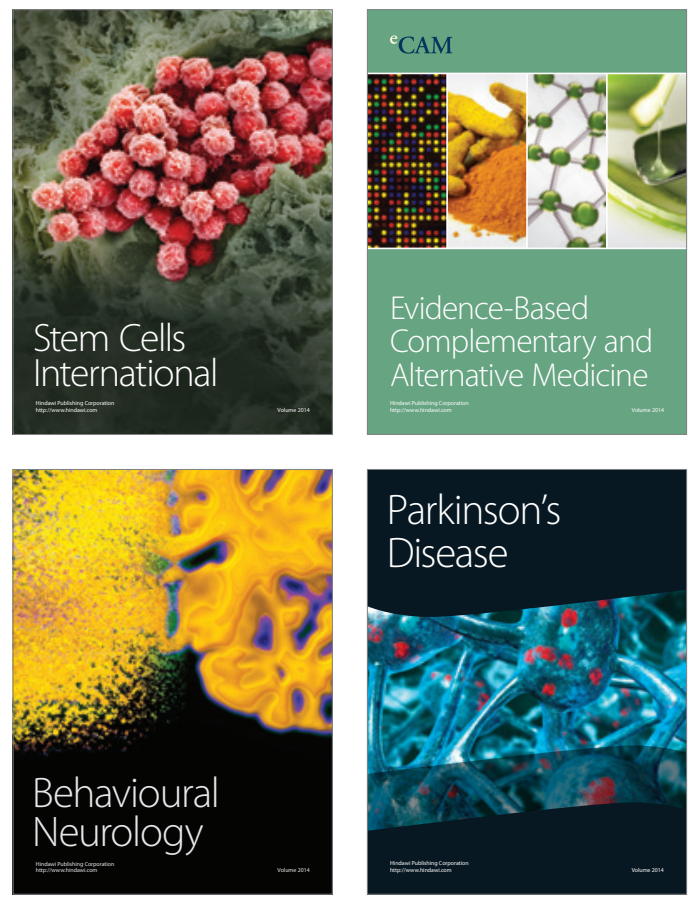
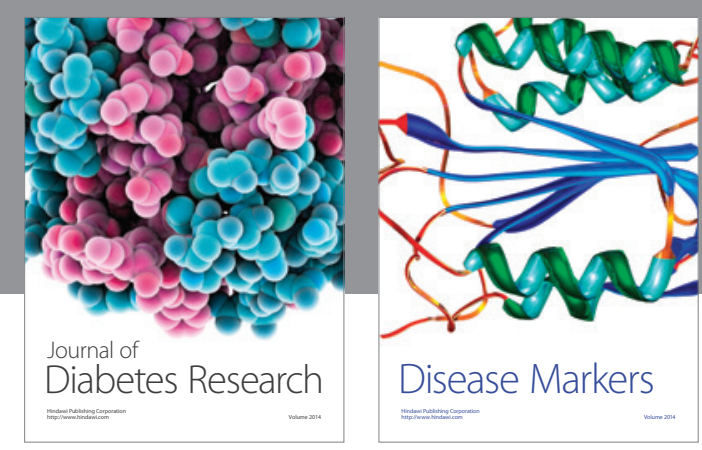

Disease Markers
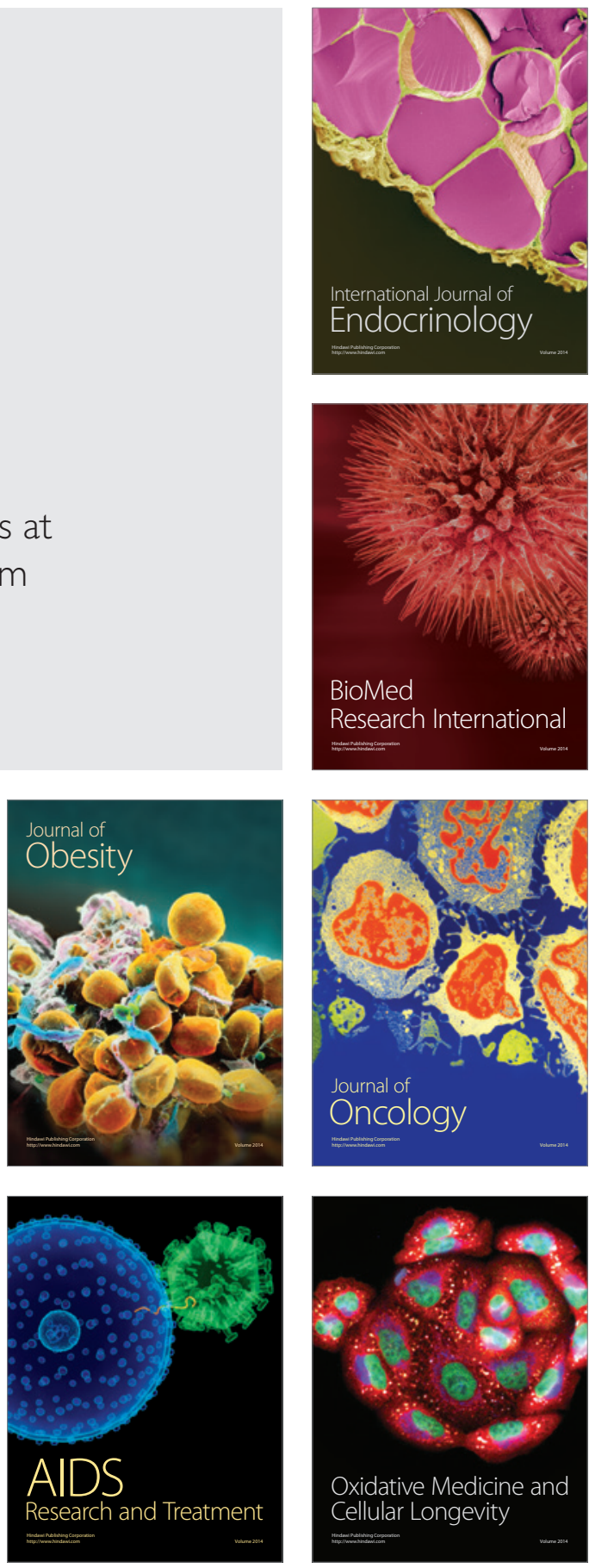